\title{
HANNA TALIKKA
}

\section{The search for happiness in the eighteenth century and today}

$\mathrm{T}$ he changing world of the eighteenth century and the preceding centuries challenged the traditional view of happiness and good life. Thinkers of the eighteenth century pursued happiness through their texts in various ways. By reading these texts we can notice that most of the key elements in our thinking today derive from the eighteenth century. A parallel can be seen between Jean-Jacques Rousseau's idea of the good life and today's view of happiness. Rousseau didn't think that progress was always leading towards a better life. Today the currently rising trend is to revert to natural ways of living and to criticise the negative progress that has led to pollution, isolation and depression. This connection between Rousseau's and today's thinking shows that people deliberate over the same questions regardless of the period of time. We can see that the eighteenth century includes those roots of thought and those questions which have been developing and have been a part of the general discussion all the way to the present moment.

WRITINGS OF THE EIGHTEENTH CENTURY exhibit a need to define a new premise for a good life and happiness. What is worth striving for: truth, power, education, or pleasure? What is the best way to live, both independently and as a part of society? What does it mean to be human?

Eighteenth century thinking can be seen as having been developed by change and encounters with the unfamiliar. The changing world of the eighteenth century and the preceding centuries challenged the traditional view of humanity, making it necessary to introduce a new definition. In a similar vein, the explorations of the Early Modern period, a high regard for classical antiquity, the emergence of industrialisation, and the encountering of other cultures forced
European culture to redefine itself. Other cultures often stood for different values and ways of living, which led to both questioning and defending the morals and customs of European culture.

The century was also attempting to find its place in history by defining itself as the period of reason and progress. Furthermore, criticism of religion shook the foundations of morality, which consequently had to turn to reason in order to find a new basis. In my view, all of this is visible in the texts that this period produced. Travel literature, as for example the travelogues of James Cook, described indigenous cultures, and some writers endeavoured to account for the superiority of European culture, while others criticised it. Philosophers deliberated over matters such as human nature, thought and mind, but in addition they debated about the best possible ways of living together. Yet literature might concentrate on illustrating pleasures-one of the ways of striving towards happiness.

Anyone who reads the thoughts of the eighteenth century thinkers may notice that the subject matter does not differ substantially compared with contemporary literature; Questions of the good life and personal development are also discussed today. However, this familiarity may be deceptive. We cannot presume that Immanuel Kant, René Descartes or any other writers of the eighteenth century understood the themes of their period as we understand them now. Nevertheless, it is extremely tempting to see parallels between both time periods.

Especially surprising in their topicality were Rousseau's ponderings on humanity and happiness, which had been inspired by encounters with Native Americans. However, his thinking did not quite match the general line of thought. Already in the seventeenth 
century, Thomas Hobbes had taken as his point of departure the suffering and unhappiness of humans in the state of nature, from which men could remove themselves by establishing ownership and a society that would defend their lives. In fact, one idea which is often connected to the eighteenth century, is that development and progress lead towards happiness and harmony. Rousseau, however, was not trying to return to the past, to the state of nature and to the era of the 'noble savage.' Instead, he merely created a revolutionary idea, according to which progress does not always lead towards a better life. He saw that society was artificial and detrimental to human happiness. According to Rousseau, the development from the state of nature to civilisation was actually not progress but regress.

Rousseau's thoughts are very much alive. Even up until the 196os the adult generation believed that their children would inherit a better future. Today, however, it is generally anticipated that the future will bring not only good things in its wake, and that, in actuality, everything used to be better. The currently rising trend is to revert to natural ways of living, to favour home-made, or even raw food, to slow down in the work pace, to reduce the number of one's possessions, to move to the countryside and to reset the cycle of development that has led to hard values, pollution, isolation and depression. The words natural and nature are becoming popular in commercial argumentation, whether it is about food, cars, travel or cosmetics.

We are not returning to the primitive state of nature, but an increasing number of people are taking a critical stance towards development, which was previously thought to bring nothing but good things with it. Just as Rousseau thought, we cannot stop progress or return to the wild, but rather we endeavour to turn progress towards the right direction. Are those contemporary people who try to maintain a slower pace and favour organic food in some way the heirs of Rousseau's thinking? Is this sort of a comparison even thinkable? Nature and naturalness nevertheless mean very different things to Rousseau and to people of today, but the basic thought shares some of these similarities.

It seems that people deliberate over the same questions regardless of the period of time. Still, thinking in the eighteenth century includes in a condensed form those roots of thought and those questions which have been developing and been a part of the general discussion all the way to the present moment. The most interesting aspects to notice are not the dif- ferences in the thinking between these two periods, but the similarities, which show how far away the sources of our ideas lie. After all, we are still striving for the same happiness and the same good life.

\section{Translated by Aleksi Mäkilähde.}

Hanna Talikka is a student of General History at the University of Turku. She is particularly interested in the culture of the eighteenth century, Enlightenment philosophy and philosophy of history. E-mail:

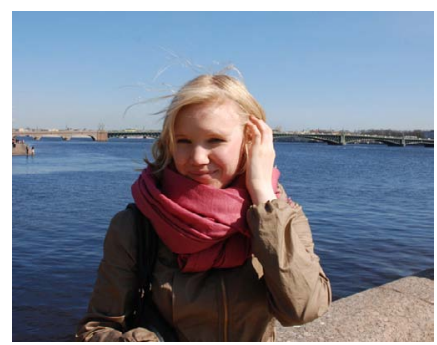
hmtali(at)utu.fi. 